\title{
REVIEW
}

\section{ABSCOPAL EFFECTS INDUCED BY LOCALIZED INTERVENTIONS IN ONCOLOGICAL PATIENTS}

\author{
E. Ventura ${ }^{1,2}$, A. Costa ${ }^{1,2}$, R. B. Dominguez ${ }^{1,2}$, G. Romano ${ }^{1}$ \\ ${ }^{1}$ College of Science and Technology, Temple University, Philadelphia, PA, USA \\ ${ }^{2}$ Sbarro Health Research Organization, Philadelphia, PA, USA
}

\section{CORRESPONDING AUTHOR:}

Gaetano Romano

College of Science and Technology

Temple University, Bio-Life Science Bldg. Room 456B

$1900 \mathrm{~N} 12^{\text {th }}$ Street

Philadelphia 19122, PA, USA

E-mail: gromano@temple.edu

ORCID: 0000-0002-6340-5879

Doi: $10.48286 / a r o .2021 .29$

History

Received: Oct 28, 2021

Accepted: Nov 17, 2021

Published: Dec 1, 2021

\begin{abstract}
Abscopal, or out-of-fields effects were reported among a number of oncological patients, who were treated with radiation therapy in combination with immune checkpoints inhibitors. The radiations induce a localized immunogenic cell death within the malignant tissues of the irradiated area. Necro-apoptotic cancer cells, in turn, stimulate tumor-specific immune responses in oncological patients, who were previously treated with immune checkpoints inhibitors. Consequently, the host immune system is able to target
\end{abstract}

\section{KEY WORDS}

Abscopal effects; radiation therapy; cancer immunotherapy; CTLA4; PD1; PDL1; PDL2; immunomodulators; immunogenic cell death; oncolytic viruses; oncolytic peptides. malignant cells that are present in various parts of the organism. Similar findings were observed in cancer immunotherapy clinical trials that combined immune checkpoints inhibitors with oncolytic viruses, immunomodulatory agents and chemotherapeutics, whereas some clinical trials are underway to combine immune checkpoints with focused ultrasound techniques.

Clinical studies are currently in progress to increase the frequency and the efficacy of abscopal effects among oncological patients.

\section{IMPACT STATEMENT}

This article covers the most recent findings in the field of oncology. Immune checkpoints inhibitors have been utilized in clinical trials in combination with therapeutic agents that induce traumatic cell death in malignant tissues, which, in turn, may resultls in system immune responses against the tumor. 


\section{INTRODUCTION}

Radiation therapy is an important technique for the treatment of malignancies $(1,2)$. Roughly $60 \%$ of oncological patients receive radiation therapy, often in combination with chemotherapy and/or surgery (1-6). Radiations can be administered into patients either as external-beam radiation therapy (EBRT), or internal radiotherapy $(1,7,8)$. EBRT utilizes collimated $\mathrm{y}$-rays, X-rays and particle therapy $(1,7,8)$. The latter comprises protons, carbon ions (9), electrons (10, 11 ) and 10B-based neutron capture therapy (12-15). Internal radiotherapy consists of two kinds of methodologies, such as brachytherapy and systemic radiation therapy (7). Brachytherapy utilizes radioactive material incorporated inside a small capsule, which can be either implanted within the tumor mass (interstitial brachytherapy), or into a cavity that is adjacent to the tumor (intracavity brachytherapy) (7). All types of ionizing radiations induce genetic and molecular alterations in the cells, which result in substantial antiproliferative and cytotoxic outcomes, leading to malignant cell death $(16,17)$. Naturally, ionizing radiations may also affect normal tissues, generating, therefore, a variety of unwanted adverse effects in patients $(16,17)$.

The in-field irradiation consists of a radiotherapy beams that is directed against malignant tissues in a specific area of the body (18). Over the decades, the energy and intensity of the incident radiation were remarkably enhanced, while the delivered dose was sharply restricted to the target, in order to reduce the detrimental side effects in healthy tissues and organs. To this end, more selective techniques have been developed, such as stereotactic ablative radiotherapy (SABR) and stereotactic radiosurgery (SRS) that are regulated with high precision either by computed tomography (CT)-, or magnetic resonance imaging (MRI)-based imaging systems (19-21), which allow for a more selective detection and destruction of small tumor masses, such as oligometastases and early-stage malignancies (19, 22-28).

Interestingly, the radiation beam may also affect tissues and/or cells that are external to the irradiated target $(18,21)$. These phenomena were termed out-of-field, or abscopal effects (29). Studies in the 1950 s reported a variety of radiation-derived effects in tissues that were far away from the irradiated site (29). The out-of-field effects induced a wide variety of biological artifacts, such as chromosomal aberrations, genetic instability, abnormal gene expression, radiation-induced malignant transformation in normal cells, either increased resistance or sensitivity to radiations, various types of cell death and, intriguingly, regression of non-irradiated tumor masses $(21,30,31)$. The latter finding attracted suddenly the interest of the oncologists. However, the spontaneous out-of-field tumor remissions were very rare among oncological patients and were referred to as abscopal effects $(3,21,32,33)$.

A considerable increase in radiation therapy-related abscopal effects among oncological patients was reported in the last years, in clinical trials that utilized immune checkpoints inhibitors either in combination with radiation therapy (figure 1) (3, $21,32-34)$, or with oncolytic viruses (34). Several cancer immunotherapy clinical trials were conducted in the last decade (34-41), which used monoclonal antibodies for the inhibition of immune checkpoint systems, such as the cytotoxic $T$ lymphocyte antigen 4 (CTLA4), programmed cell death protein 1 (PD1), programmed cell death 1 ligand 1 (PDL1) and PDL2 (34, 42-47). Oncological patients were enrolled in the cancer immunotherapy clinical trials for the treatment of hematological malignancies and for a wide range of solid tumors (3454). The clinical outcomes were rather promising among a considerable proportion of participants (34-54). Over the last five years, most cancer immunotherapy clinical trials administered immune checkpoints inhibitors in combination with other treatments, such as immunomodulators (54-58), chemotherapeutic agents (57), radiation therapy (58) and oncolytic viruses (34). In summary, immune checkpoint inhibitors predispose the host immune system of the patient to tackle the cancer cells, whereas a localized therapeutic intervention enhances the efficiency of the immune response in eliminating tumor deposits, which may result in a systemic response against the malignancy. This review describes the strategies that have been adopted in cancer immunotherapy clinical trials to optimize abscopal effects in oncological patients.

\section{IMMUNOGENIC CELL DEATH AND ABSCOPAL EFFECTS}

As anticipated, in radiobiology the out-of-field effects include a wide range of possible interactions 


\begin{tabular}{|c|c|}
\hline $1950 \mathrm{~s}$ & $\begin{array}{l}\text { The term abscopal } \\
\text { effects is formulated by } \\
\text { radio-biologists. }\end{array}$ \\
\hline & $\begin{array}{l}\text { Sporadic cases of } \\
\text { abscopal effects are } \\
\text { reported in patients with } \\
\text { cancer, following } \\
\text { radiation therapy } \\
\text { through the decades. }\end{array}$ \\
\hline \multirow{2}{*}{ Mid-2010s } & \multirow{2}{*}{$\begin{array}{l}\text { A substantial increase } \\
\text { of abscopal effects are } \\
\text { reported in patients } \\
\text { with cancer, following } \\
\text { the treatment with } \\
\text { immuno-checkpoint } \\
\text { inhibitors combined } \\
\text { with radiation therapy. }\end{array}$} \\
\hline & \\
\hline \multirow{2}{*}{ Late-2010s } & \multirow{2}{*}{$\begin{array}{l}\text { Abscopal effects are } \\
\text { also reported in clinical } \\
\text { trials that combined } \\
\text { immuno-checkpoint } \\
\text { inhibitors either with } \\
\text { oncolytic viruses, or } \\
\text { chemotherapy. }\end{array}$} \\
\hline & \\
\hline $\begin{array}{l}\text { Late-2010s } \\
\text { early } 2020 \mathrm{~s}\end{array}$ & $\begin{array}{l}\text { Early stage clinical } \\
\text { trials are using focused } \\
\text { ultrasound to treat } \\
\text { prostate cancer. }\end{array}$ \\
\hline
\end{tabular}

Figure 1. Timeline of abscopal effects reported in cancer therapy and in clinical trials.

on organs and on healthy and/or malignant tissues, such as genetic and/or epigenetic modifications that may induce secondary malignancies, either enhanced resistance or susceptibility to the radiations, necrotic and/or apoptotic cell death and other types of events that may be responsible to tissue and/or organ damage (21, 30-32). Oncologists, however, are mainly interested in characterizing the possibility that a localized intervention may ultimately stimulate a systemic reaction of the organism against cancerous tissues $(3,21,32,33)$. The localized therapeutic intervention may be based on radiation therapy, chemotherapeutics, oncolytic viruses, lysing peptides and so on. Of course, a particular emphasis has been placed on radiation therapy over the last years, because of the significant increase of reported abscopal effects in oncological patients, who were treated with immune checkpoints inhibitors in combination with radiation therapy.

Radiation therapy technology has been significantly improved over the decades, in order to increase the specificity of the in-field effect on the area of the tumor $(19,32,59,60,61)$. The radiation portals of old instruments were wider and often affected healthy tissues and/or organs contiguous to the area of the irradiated tumor (61-63). A more specific in-field application for the tumor of recent instruments minimizes the collateral damages of the radiations to the healthy tissues and organs of the patients (19, $32,59,60,61)$. The hematopoietic system has been particularly exposed to the detrimental effects of less specific radiation portals of old instruments, with consequent immunosuppression of the subject (61-63). In addition to the radiation portal size, other out-of-field effects may be related to scattered radiations inside the body (64-66), leaky radiations from the source of the instrument that produces the beam $(30,67)$ and bystander effects that are induced in response to the radiations $(21,30,33,60$, 68 ). The impact of the radiation on the surface of the target may deflect a portion of the beam, which, in turn, diffuses inside the body and affects other organs and tissues (64-66), whereas various bystander effects may derive from factors that are secreted or released by irradiated malignant cells and/or surrounding normal cells tissues or cells $(21,30,33,60$, 68). The secreted factors, in turn, may interact with the tissues of distant organs $(21,30,33,60,68)$.

The major focus of oncologists consists of improving the efficiency of clinical protocols leading to abscopal effects, which derive from an intervention in a restricted area of the body that ultimately results in a systemic response against the tumor $(3,21,32$, 33). The characterization of abscopal effects in oncological patients has demonstrated an involvement of the immune system $(3,21,32-34)$. In fact, abscopal effects are more frequent when the immune checkpoint inhibitors are combined with radiation therapy for the treatment of the oncological patients $(3,21$, $32-34,69)$. A common adverse effect of radiations in cancer therapy is related to the immune suppression of the subjects. However, many clinical trials showed that localized interventions may eventually trigger systemic immune responses against the tumor in a significant number of patients $(18,21$, 30-34). The highly collimated radiation that targets the in-field area of the tumor induces necrotic and/ or apoptotic cell death (figure 2), along with epigenetic mutations that induce phenotypic alterations 
of cancer cells, which may increase the expression levels of a variety of molecules on the surface of malignant cells, such as tumor-associated antigens, cell death receptors and adhesion molecules (34, 70, 71). Taken together, the phenotypic alterations of malignant cells and the necro-apoptotic cell death produce a sort of immunogenic hub, which may act as an in situ vaccine against cancer cells (figure 2) (18). Naturally, the use of immune checkpoint inhibitors increases the efficiency of the radiation-induced in situ vaccine, which may lead to a systemic immune response against the malignancy $(18,21,30-34)$.

Overall, radiation therapy is utilized to induce genetic and molecular injuries in tumor cells, which may lead to proliferative arrest (72), activation of caspases resulting in apoptosis $(73,74)$ and different kinds of programmed necrotic cell death, or necroptosis (75-77). Intracellular and extracellular factors take place in the regulation of the traumatic cell death that leads to necroptosis (table I). The so-called necroptotic pathway is associated with two intracellular axis: (I) the mixed lineage kinase domain-like (MLKL)-protein and the receptor-interacting protein kinase 3 (RIPK3) (73-75); (II) the poly(ADP-ribose) polymerase 1 (PARP1) and the apoptosis-inducing factor mitochondrion-associated 1 (AIFM1) $(78,79)$. The PARP1 and AIFM1-related necroptotic cell death is also known as parthanatos, which is a Greek mythology-derived term for messenger of death (78, 79). The tumor suppressor protein p53 is another important player in mediating the elimination of the cells that cannot complete the mitotic program, due to radiation-induced mitotic catastrophe (80-82).

Danger associated molecular pattern molecules (DAMPs) can also take a role in modulating radiation therapy-mediated host immune responses (table I) $(83,84)$. DAMPs are discharged by injured and/or dying cells and comprise chromatin, fragments of double-stranded DNA, RNA molecules and high-mobility group protein 1 (HMGB-1) (83, 84). The released DAMPs are then recognized by the toll-like receptors (TLRs), following a mechanism that is analogous to the pathogen-associated molecular pattern molecules (83). The interaction between DAMPs and TLRs leads to immunogenic cell death that requires the activation of mac-

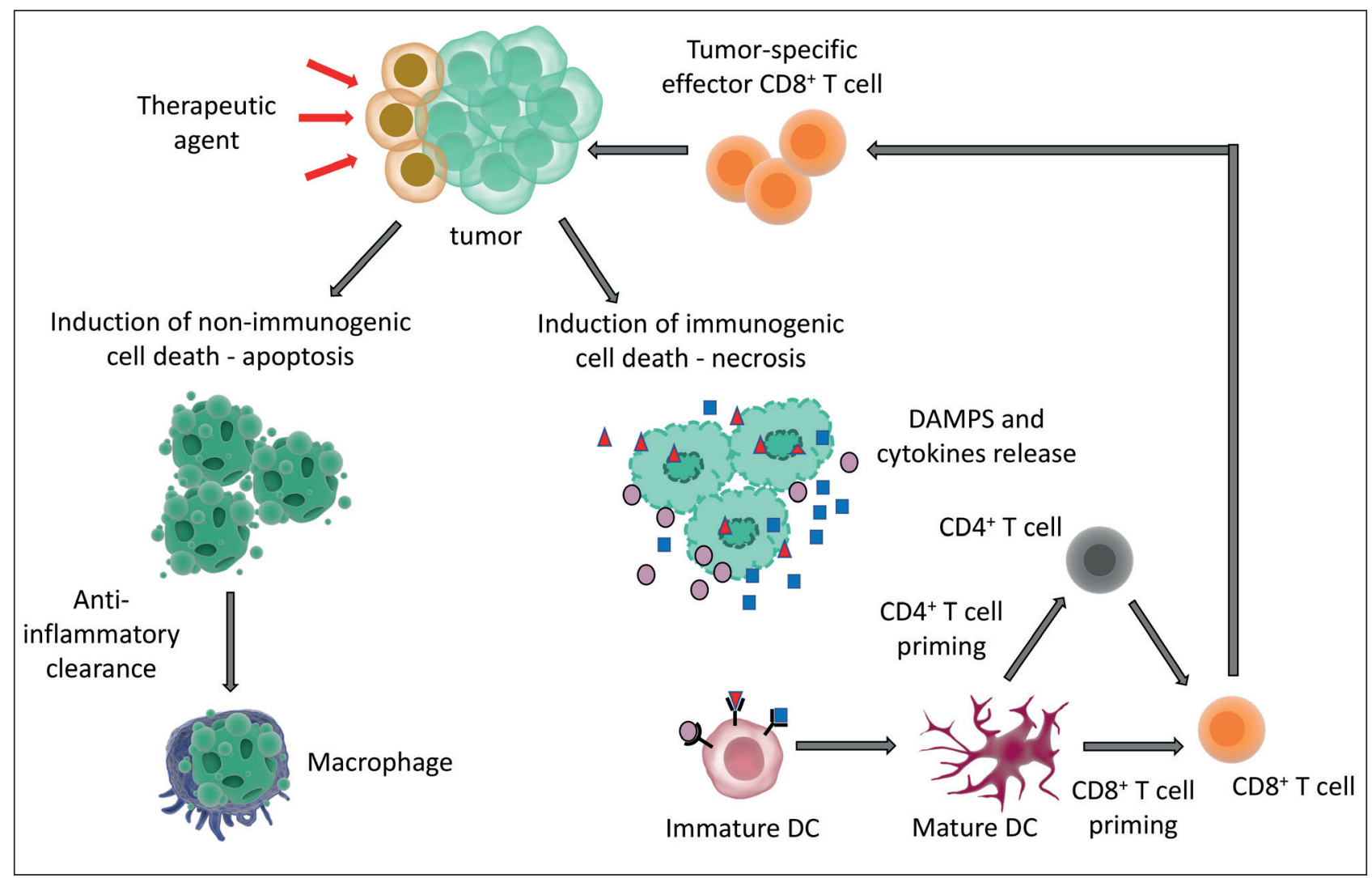

Figure 2. Immunogenic and non-immunogenic cell death. A therapeutic agent destroys part of the malignant cells of the tumor mass. Some cells may undergo apoptosis, which does not elicit inflammatory reactions in the affected tissues, or organs. The cellular debris are subsequently removed by macrophages. Conversely, the necrotic or necro-apoptotic cell death releases cellular debris and other factors, which stimulate inflammatory reactions through DAMPs. The inflammation may ultimately lead to the maturation of dendritic cells, which then program tumor-specific cytotoxic CD8-positive T cells to attack the remaining cancer cells in the tumor mass and, possibly, in other regions of the organism. 
rophages through chemokines and/or cytokines, which point the other elements of the immune system to intervene and remove the origin of the distress signals and attempt to promote homeostasis and healing $(17,85-91)$.

There are many other factors that derive from radiation-induced injuries of cancer cells, which release certain components that affect several other cells via bystander effects (table I). For example, before dying irradiated cells quite often secrete cytotoxic mediators based on reactive oxygen and nitrogen species $(21,92,93)$, together with certain cytokines, such as tumor necrosis factor $\alpha$ (TNF $\alpha$ interleukin (IL)-6, IL-8 and transforming growth factor $\beta 1$ (TGF $\beta 1)$ (94-97). The cytotoxic mediators are responsible for short range bystander effects, which involve non-irradiated malignant cells that are contiguous to irradiated cells $(16,98,99)$.

The interpretation of the influence of ionizing radiations on tumor vascularization is rather controversial (100-106). Radiation therapy has also been designed to affect the tumor microenvironment, which is an important regulator of tumor vascularization (102). Therefore, the irradiation of the tumor niche should result in the inhibition of neoangiogenesis in the areas that surround the tumor mass. However, the analysis of the irradiation-induced clinical effects on tumor vascularization has provided some unexpected findings (106). In this respect, a clinical study on the effects of radiation therapy on neovascularization observed the reformation of blood vessels around relapsing tumor masses (104). Additional studies revealed that radiations also have the potential to increase the epithelial-mesenchymal transition of cancer cells, along with enhanced migration, metastasis, invasion and angiogenesis (106). Some clinical trials are combining radiation therapy with antiangiogenic factors to make the targeting of the tumor microenvironment more effective and to avoid the reconstitution of neovascularization $(98,107-109)$.

\section{ABSCOPAL EFFECTS IN RADIATION THERAPY}

As already discussed, the combination of immune checkpoints inhibitors with radiation therapy provided a substantial increment of abscopal effects among oncological patients.

Systemic immune responses were reported in two clinical trials, in which patients with melanoma were treated with the CTLA4 inhibitor termed ipilimumab and radiation therapy $(110,111)$. In one trial, the clinical outcome of the patient exhibited tumor mass reduction, a rise in $\mathrm{CD} 4+\mathrm{ICOS}{ }^{\text {high }} \mathrm{T}$ cells counts and antibodies-mediated responses to the cancer-testis antigen NY-ESO-1 (110). The other trial dealt with the treatment of a patient with melanoma, who had brain and nodal metastasis and was treated with ipilimumab and stereotactic radiosurgery into the brain metastasis (111). A complete brain tumor remission was observed, along with the resolution of nodal metastases (111).

Enhanced systemic immune responses were reported among patients with advanced melanoma, who received radiation therapy in combination with ipilimumab (112). The total number of patients enrolled in the trial was 101 . A cohort of 70 patients received the double treatment of radiations and ipilimumab, whereas a second cohort of 31 patients was treated with ipilimumab alone (112). No differences in toxicity were observed between the two groups of patients. The rates of complete responses were in the double treatment group was $25.7 \%$, whereas the complete responses rates of the single treatment group were 6.5\% (112).

Thirty-five patients with standard therapy refractory metastasized solid tumors either in the lung, or in the liver were enrolled in a phase I clinical trial, which used ipilimumab in combination with SABR (20). Significant clinical benefits were reported in 7

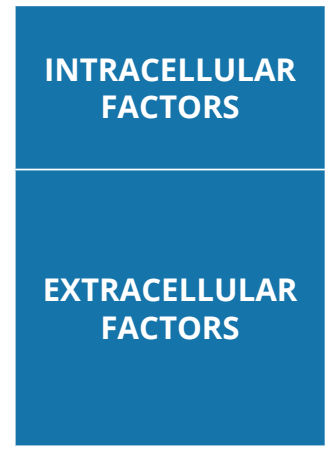

Mixed lineage kinase domainlike (MLKL)-protein and the receptor-interacting protein kinase 3 (RIPK3) axis.

Danger associated molecular pattern molecules (DAMPs) and toll-like receptors (TLRs).
Poly(ADP-ribose) polymerase 1 (PARP1) and the apoptosis-inducing factor mitochondrion-associated 1 (AIFM1) axis (parthanatos).

Bystander effects induced by:

- reactive oxygen and nitrogen species;

tumor necrosis factor a (TNFa);

interleukin (IL)-6 and IL-8; transforming growth factor b1

(TGFb1).

Table I. List of factors that regulate the necroptotic pathways induced by traumatic cell death. 
patients, who exhibited either a partial response, or a stable disease period that lasted more than 6 months (20). The cohort of patients with clinical benefits had substantial augment of peripheral blood $C D 8^{+} T$ cells (20).

Abscopal effects were also reported in clinical studies that utilized SABR alone (30). Twenty-eight patients with renal carcinoma were treated with SABR (113). Abscopal effects leading to tumor remissions were observed in 4 patients of the clinical study (113). A complete metastatic disease regression was reported in three patients that exhibited abscopal effects-related clinical benefits (111). In addition, no recurrence of the tumor was observed after the intervention in periods that ranged from 2 to 4 years (113).

SABR-related abscopal effects were observed in a patient with renal carcinoma (114). The out-of-field effects caused the remission of pulmonary metastases and of lymph nodes metastases (114). Regrettably, a contemporaneous relapse of the disease involved the brain, indicating that in this case abscopal effects were not able to pass through the bloodbrain barrier (114).

A patient with synchronous primary lung cancer was treated with chemoradiation therapy to the primary adenocarcinoma situated in the left lung (115). Five months later, SABR was used to target the primary tumor mass in the right lung. Abscopal effects resulting in the remission of metastases were reported 5 months post-SABR treatment (115).

Twenty-three cases of abscopal effects were identified in retrospective studies on radiation oncology clinical literature from 1960 until July 2014 (33). The searches were conducted in Medline and Embase. The patients had either solid tumors, or blood-related cancers and were treated either with radiation therapy alone, or in combination with immunotherapy (33).

Abscopal effects were also observed in another Medline search, for the retrospective study on patients with metastatic melanoma, who underwent radiation therapy combined with ipilimumab from 2009 until 2017 (116). The search identified 16 clinical trials that involved 451 patients. Abscopal effects were observed in an average of $26.5 \%$ of patients and the median overall survival was 19 months (116).

Clinical studies are currently characterizing the effects of hypofractionated radiation therapy combined with immune checkpoint inhibitors in patients with non-small cell lung cancer (117), whereas a preclinical study reported an increase of abscopal effects in a mouse model for breast cancer, following fractionated doses of radiations combined with immune checkpoint inhibitors (118).

\section{ABSCOPAL EFFECTS INDUCED BY OTHER THERAPEUTIC AGENTS}

In addition to radiation therapy, immunogenic cell death-related abscopal effects can be triggered by a variety of therapeutic agents that lyse malignant cells. For instance, oncolytic viruses have been used either alone, or in combination with immune checkpoints inhibitors in some clinical studies for the treatment of various tumors $(34,119-125)$. Some oncolytic viruses were produced to encode immunomodulatory agents, such as cytokines (34). Following the entry into the malignant cells, the oncolytic viral-encoded cytokines are expressed and contribute to increase the host immune responses against tumor-associated antigens of lysed cancer cells (34). The oncolytic herpesvirus talimogene laherparepvec (T-vec) was utilized in a clinical trial for the treatment of patients with advanced melanoma (34). T-vec was engineered to encode the granulocyte-macrophage colony-stimulating factor (GM-CSF), which attracts the cells of the immune system and then stimulates their proliferation (127-131). However, the immunosuppression that affects most patients with cancer is a major obstacle for the effective application of oncolytic viruses in therapy (34). Therefore, immune checkpoints inhibitors were utilized in conjunction with oncolytic viruses to boost the host immune responses in oncological patients (34, 129, 130, 132-134). For instance, ipilimumab and T-vec were administered into patients with unresectable stage IIIB-IV melanoma (135). Complete remission was reported in 4 patients and the clinical data showed that the treatment was safe (135).

Preclinical studies were conducted in animal models to characterize the recombinant vaccinia virus $\mathrm{VV}_{\mathrm{WR}}$-TK-RR-Fcu1 (136) and the chimeric parapoxvirus CF189 (137). Targeting of secondary tumor masses in animals were observed in both studies. Another preclinical testing was carried out to study the anti-cancer effects of the oncolytic peptide LTX315 , which was administered into animals along with an immune checkpoint inhibitor to test their ability to clear subcutaneous implantations of tumor cell lines (138). The oncolytic peptide LTX-315 produces pores through the cellular membrane 
and then attacks the mitochondria. At this stage, the targeted malignant cells release DAMPs and undergo immunogenic cell death (138).

An emerging technique in cancer therapy is based on high intensity focused ultrasound, which can be used to target the tumor microenvironment and to induce tissue damage to the tumor mass (139). Focused ultrasound delivers mechanical waves that are centered at small region of the target tissue and comprises four types of applications, such as histotripsy, mechanical perturbation, thermal ablation and hyperthermia/thermal stress (139). Consequently, the high density of the delivered energy is absorbed by the treated area. The local heating and/or mechanical stimulations may cause tissue damage to the irradiated tumor site, with resultant immunogenic cell death, followed by the release of tumor associated antigens and DAMPs (figure 2). High intensity focused ultrasound has been used for the treatment of patients with prostate cancer, with promising results at the time of the treatment $(140,142)$. However, it is too early for an evaluation of the long-term effects of the therapeutic applications in patients with prostate cancer, because the trials are recent.

\section{CONCLUSIONS}

The activation of the host immune system induced by immune checkpoints inhibitors, along with a localized therapeutic intervention that causes immunogenic cell death in the targeted malignant mass are the essential key elements that may lead to a systemic response against the tumor in oncological patients. Clinical trials and preclinical studies are currently in progress to optimize the efficiency of abscopal effects in patients with cancer. These studies involve a variety of therapeutic agents, which are utilized for the treatment of several types of malignancies. For the moment, a major emphasis has been placed on radiation therapy, chemotherapeutics and immunomodulators, followed by oncolytic viruses and focused ultrasound, while other promising therapeutic agents are currently under charac- terization at the preclinical stage, such as oncolytic peptides. The current priority in the field of cancer therapy is the achievement of a more efficient induction of abscopal effects in patients with cancer. Unfortunately, molecular and/or genetic markers associated with the onset of abscopal effects in patients are currently missing (142). The identification and characterization of biomarkers for the prediction and optimization of abscopal effects are certainly challenging tasks for the oncologists.

\section{ACKNOWLEDGMENTS}

This manuscript is dedicated to the loving memory of Leonida Stringhini. Part of the material to produce the two figures was very kindly provided by https://www.somersault1824.com/. This work was supported by the Commonwealth of Pennsylvania and the Sbarro Health Research Organization (SHRO).

\section{ETHICS}

\section{Fundings}

EV, AC and RBD are supproted by the Commonwealth of Pennsylvania and the Sbarro Health Research Organization (SHRO).

\section{Conflict of interests}

The authors have declared no conflict of interests.

\section{Availability of data and material}

All the data supporting the findings of this study are available within the article.

\section{Authors' contribution}

All the authors contributed equally to conception, data collection, analysis and writing of this paper.

\section{Ethical approval}

N/A 


\section{REFERENCES}

1. Thariat J, Hannoun-Levi JM, Sun Myint A, Vuong T, Gérard JP. Past, present, and future of radiotherapy for the benefit of patients. Nat Rev Clin Oncol 2013;10(1):52-60.

2. Bernier J, Hall EJ, Giaccia A. Radiation oncology: a century of achievements. Nat Rev Cancer 2004;4(9):737-47.

3. Brix N, Tiefenthaller A, Anders H, Belka C, Lauber K. Abscopal, immunological effects of radiotherapy: Narrowing the gap between clinical and preclinical experiences. Immunol Rev 2017;280(1):249-79.

4. Mitchell MP, Sharma P. The Use of Surgery and Radiotherapy as Treatment of Regional Nodes in Breast Cancer Patients. Oncology (Williston Park) 2018;32(6):e52-e64.

5. Schernberg A, Rivin Del Campo E, Rousseau B, et al. Adjuvant chemoradiation for gastric carcinoma: State of the art and perspectives. Clin Transl Radiat Oncol 2018;10:13-22.

6. Orth M, Lauber K, Niyazi M, et al. Current concepts in clinical radiation oncology. Radiat Environ Biophys 2014;53(1):1-29.

7. Ahmad SS, Duke S, Jena R, Williams MV, Burnet NG. Advances in radiotherapy. BMJ 2012;345:e7765.

8. Vacchelli E, Vitale I, Tartour E, Eggermont A. Trial Watch: Anticancer radioimmunotherapy. Oncoimmunology 2013;2(9): e25595.

9. Combs SE. Proton and Carbon Ion Therapy of Intracranial Gliomas. Prog Neurol Surg 2018;32:57-65.

10. Sweeting RS, Deal AM, Llaguna $\mathrm{OH}$, et al. Intraoperative electron radiation therapy as an important treatment modality in retroperitoneal sarcoma. J Surg Res 2013;185(1):245-9.

11. Stucky CC, Wasif N, Ashman JB, et al. Excellent local control with preoperative radiation therapy, surgical resection, and intra-operative electron radiation therapy for retroperitoneal sarcoma. J Surg Oncol 2014;109(8):798-803.

12. Miyatake SI, Kawabata S, Hiramatsu R, et al. Boron Neutron Capture Therapy of Malignant Gliomas. Prog Neurol Surg 2018;32:48-56.

13. Wang LW, Liu YH, Chou FI, Jiang SH. Clinical trials for treating recurrent head and neck cancer with boron neutron capture therapy using the Tsing-Hua Open Pool Reactor. Cancer Commun (Lond) 2018;38(1): 37.

14. Barth RF, Zhang Z, Liu T. A realistic appraisal of boron neutron capture therapy as a cancer treatment modality. Cancer Commun (Lond) 2018;38(1):36.

15. Barth RF, Mi P, Yang W. Boron delivery agents for neutron capture therapy of cancer. Cancer Commun (Lond) 2018;38(1):35.

16. Prise KM, O' Sullivan JM. Radiation-induced bystander signalling in cancer therapy. Nat Rev Cancer 2009;9(5):351-60.

17. Garg AD, Krysko DV, Vandenabeele P, Agostinis $P$. The emergence of phox-ER stress induced immunogenic apoptosis. Oncoimmunology 2012;1(5):786-8.

18. Formenti SC, Demaria S. Radiation therapy to convert the tumor into an in situ vaccine. Int J Radiat Oncol Biol Phys 2012;84(4):879-80.

19. Chang JY. Stereotactic ablative radiotherapy: aim for a cure of cancer. Ann Transl Med 2015;3(1):12.

20. Tang C, Welsh JW, de Groot $P$, et al. Ipilimumab with Stereotactic Ablative Radiation Therapy: Phase I Results and Immunologic Correlates from Peripheral T Cells. Clin Cancer Res 2017;23(6):1388-96.

21. Hanna GG, Coyle VM, Prise KM. Immune modulation in advanced radiotherapies: Targeting out-of-field effects. Cancer Lett 2015;368(2):246-51.

22. Ronden MI, Palma D, Slotman BJ, et al. Brief Report on Radiological Changes following Stereotactic Ablative Radiotherapy (SABR) for Early-Stage Lung Tumors: A Pictorial Essay. J Thorac Oncol 2018;13(6):855-62.

23. Mutsaers A, Chen H, Louie AV. Stereotactic ablative radiation therapy in lung cancer: an emerging standard. Curr Opin Pulm Med 2018;24(4):335-42.

24. Barry A, Fyles A. Establishing the Role of Stereotactic Ablative Body Radiotherapy in Early-Stage Breast Cancer. Int J Breast Cancer 2018;2018:2734820.

25. Paik EK, Kim MS, Seo YS, et al. Feasibility of split-course stereotactic ablative radiotherapy for oligometastases. Jpn J Clin Oncol 2018;48(6):548-54.

26. Mihai A, Mu Y, Armstrong J, et al. Patients with colorectal lung oligometastases (L-OMD) treated by dose adapted SABR at diagnosis of oligo- 
metastatic disease have better outcomes than patients previously treated for their metastatic disease. J Radiosurg SBRT 2017;5(1):43-53.

27. Bergsma DP, Salama JK, Singh DP, et al. Radiotherapy for Oligometastatic Lung Cancer. Front Oncol 2017;7:210.

28. Kennedy TAC, Corkum MT, Louie AV. Stereotactic radiotherapy in oligometastatic cancer. Chin Clin Oncol 2017;6(Suppl 2):S16.

29. Mole RH. Whole body irradiation - radiobiology or medicine? Br J. Radiol 1953;26(305):234-41.

30. Siva S, MacManus MP, Martin RF, Martin OA. Abscopal effects of radiation therapy: a clinical review for the radiobiologist. Cancer Lett 2015;356(1):82-90.

31. Siva S, Lobachevsky $P$, MacManus MP, et al. Radiotherapy for Non-Small Cell Lung Cancer Induces DNA Damage Response in Both Irradiated and Out-of-field Normal Tissues. Clin Cancer Res 2016;22(19):4817-26.

32. Hu ZI, McArthur HL, Ho AY. The Abscopal Effect of Radiation Therapy: What Is It and How Can We Use It in Breast Cancer? Curr Breast Cancer Rep 2017;9(1):45-51.

33. Reynders K, Illidge T, Siva S, Chang JY, De Ruysscher D. The abscopal effect of local radiotherapy: using immunotherapy to make a rare event clinically relevant. Cancer Treat Rev 2015;41(6):503-10.

34. Romano G, Gawlinski A. New frontiers in oncology: immune checkpoint inhibitors in combination therapy. Drugs Today (Barc) 2017;53(2):103-15.

35. Craig DJ, Nanavaty NS, Devanaboyina M, et al. The abscopal effect of radiation therapy. Future Oncol 2021;17(13):1683-94.

36. Janopaul-Naylor JR, Shen Y, Qian DC, Buchwald ZS. The Abscopal Effect: A Review of Pre-Clinical and Clinical Advances. Int J Mol Sci 2021;22:11061.

37. Lam SS, Zhou F, Hode T, et al. Advances in strategies and methodologies in cancer immunotherapy. Discov Med 2015;19(105):293-301.

38. Ito A, Kondo S, Tada K, Kitano S. Clinical Development of Immune Checkpoint Inhibitors. Biomed Res Int 2015;2015:605478.

39. Lee J, Kefford R, Carlino M. PD-1 and PD-L1 inhibitors in melanoma treatment: past success, present application and future challenges. Immunotherapy 2016;8(6):733-46.

40. Lyons TG, Dickler MN, Comen EE. Checkpoint Inhibitors in the Treatment of Breast Cancer. Curr Oncol Rep 2018;20(7):51.
41. Sheng J, Srivastava S, Sanghavi K, et al. Clinical Pharmacology Considerations for the Development of Immune Checkpoint Inhibitors. J Clin Pharmacol 2017;57 (Suppl 10): S26-S42.

42. Michot JM, Bigenwald C, Champiat S, et al. Immune-related adverse events with immune checkpoint blockade: a comprehensive review. Eur J Cancer 2016;54:139-48.

43. Muenst $S$, Läubli $H$, Soysal SD, et al. The immune system and cancer evasion strategies: therapeutic concepts. J Intern Med 2016;279(6):541-62.

44. Ugurel S, Röhmel J, Ascierto PA, et al. Survival of patients with advanced metastatic melanoma: The impact of novel therapies. Eur J Cancer 2016;53:125-34.

45. Callahan MK, Flaherty CR, Postow MA. Checkpoint Blockade for the Treatment of Advanced Melanoma. Cancer Treat Res 2016;167:231-50.

46. Buchbinder E, Hodi FS. Cytotoxic T lymphocyte antigen-4 and immune checkpoint blockade. J Clin Invest 2015;125(9):3377-83.

47. Tsirigotis P, Savani, BN, Nagler A. Programmed death-1 immune checkpoint blockade in the treatment of hematological malignancies. Ann Med 2016;25:1-12.

48. Lipson EJ, Drake CG. Ipilimumab: an anti-CTLA-4 antibody for metastatic melanoma. Clin Cancer Res 2011;17(22):6958-62.

49. Robert C, Thomas L, Bondarenko I, et al. Ipilimumab plus dacarbazine for previously untreated metastatic melanoma. N Engl J Med 2011;364(26):2517-26.

50. Hodi FS, O' Day SJ, McDermott DF, et al. Improved survival with ipilimumab in patients with metastatic melanoma. N Engl J Med 2010;363(8):711-23.

51. Mahoney KM, Freeman GJ, McDermott DF. The Next Immune-Checkpoint Inhibitors: PD-1/PD-L1 Blockade in Melanoma. Clin Ther 2015;37(4):764-82.

52. Hoos A, Eggermont AM, Janetzki $S$, et al. Improved Endpoints for Cancer Immunotherapy Trials. J Natl Cancer Inst 2010;102(18):1388-97.

53. Kluetz PG, Pazdur R. Looking to the future in an unprecedented time for cancer drug development. Semin Oncol 2016;43(1):2-3.

54. Maio M, Covre A, Fratta E, et al. Molecular Pathways: At the Crossroads of Cancer Epigenetics and Immunotherapy. Clin Cancer Res 2015;21(18):4040-7.

55. Covre A, Coral S, Nicolay H, et al. Antitumor activity of epigenetic immunomodulation combined 
with CTLA-4 blockade in syngeneic mouse models. Oncoimmunology 2015;4(8): e1019978.

56. Atkins MB, Larkin J. Immunotherapy Combined or Sequenced With Targeted Therapy in the Treatment of Solid Tumors: Current Perspectives. J Natl Cancer Inst 2016;108(6):djv414.

57. Luke J, Ott PA. Kinase inhibitors and immune check-point blockade for the treatment of metastatic melanoma and advanced cancer: synergistic or antagonistic? Expert Opin Pharmacother 2013;14(18):2457-62.

58. Pilones KA, Vanpouille-Box C, Demaria S. Combination of radiotherapy and immune checkpoint inhibitors. Semin Radiat Oncol 2015;25(1):28-33.

59. Steel GG, McMillan TJ, Peacock JH. The 5 Rs of radiobiology. Int J Radiat Biol 1989; 56(6):1045-8.

60. Chargari C, Magne N, Guy JB, Rancoule C, et al. Optimize and refine therapeutic index in radiation therapy: Overview of a century. Cancer Treat Rev 2016;45:58-67.

61. Baumann M, Krause M, Overgaard J, et al. Radiation oncology in the era of precision medicine. Nat Rev Cancer 2016;16:234-49.

62. Grilli G, Nothdurft W, Fliedner TM. Radiation sensitivity of human erythropoietic and granulopoietic progenitor cells in the blood and in the bone marrow. Int J Radiat Biol Relat Stud Phys Chem Med 1982;41(6):685-7.

63. Deeg HJ, Sullivan KM, Buckner CD, et al. Marrow transplantation for acute nonlymphoblastic leukemia in first remission: toxicity and longterm follow-up of patients conditioned with single dose or fractionated total body irradiation. Bone Marrow Transplant 1986; 1(2):151-7.

64. Kim DW, Chung K, Chung WK, et al. Risk of secondary cancers from scattered radiation during intensity-modulated radiotherapies for hepatocellular carcinoma. Radiat Oncol 2014;9:109.

65. Paganetti $\mathrm{H}$. Assessment of the risk for developing a second malignancy from scattered and secondary radiation in radiation therapy. Health Phys 2012;103(5):652-61.

66. St James S, Grassberger C, Lu HM. Considerations when treating lung cancer with passive scatter or active scanning proton therapy. Transl Lung Cancer Res 2018;7(2):210-5.

67. Weidlich GA, Schneider MB, Adler JR. Characterization of a Novel Revolving Radiation Collimator. Cureus 2018;10(2):e2146.

68. Bloy N, Pol J, Manic G, et al. Trial Watch: Radioimmunotherapy for oncological indications. Oncoimmunology 2014;3(9):e954929.
69. Ebner DK, Tinganelli W, Helm A, et al. The Immunoregulatory Potential of Particle Radiation in Cancer Therapy. _Front Immunol 2017;8:99.

70. Cacan E, Greer SF, Garnett-Benson C. Radiation-induced modulation of immunogenic genes in tumor cells is regulated by both histone deacetylases and DNA methyltransferases. Int J Oncol 2015;47(6):2264-75.

71. Smits KM, Melotte V, Niessen HE, et al. Epigenetics in radiotherapy: where are we heading? Radiother Oncol 2014;111(2):168-77.

72. Verheij M. Clinical biomarkers and imaging for radiotherapy-induced cell death. Cancer Metastasis Rev 2008;27(3):471-80.

73. Kroemer G, Galluzzi L, Brenner C. Mitochondrial membrane permeabilization in cell death. Physiol Rev 2007;87(1):99-163.

74. Tait SW, Green DR. Mitochondria and cell death: outer membrane permeabilization and beyond. Nat Rev Mol Cell Biol 2010;11(9621-32.

75. Linkermann A, Green DR. Necroptosis. N Engl J Med 2014;370(5):455-65.

76. Vandenabeele P, Galluzzi L, Vanden Berghe $T$, Kroemer G. Molecular mechanisms of necroptosis: an ordered cellular explosion. Nat Rev Mol Cell Biol 2010;11(10):700-14.

77. Yoon S, Kovalenko A, Bogdanov K, Wallach D. $M L K L$, the Protein that Mediates Necroptosis, Also Regulates Endosomal Trafficking and Extracellular Vesicle Generation. Immunity 2017;47(1):51-65.

78. David KK, Andrabi SA, Dawson TM, Dawson VL. Parthanatos, a messenger of death. Front Biosci (Landmark Ed) 2009;14:1116-28.

79. Fatokun AA, Dawson VL, Dawson TM. Parthanatos: mitochondrial-linked mechanisms and therapeutic opportunities. Br J Pharmacol 2014;171(8):2000-16.

80. Vousden $\mathrm{KH}$, Lane DP. p53 in health and disease. Nat Rev Mol Cell Biol 2007;8(4):275-83.

81. Vitale I, Galluzzi L, Castedo M, Kroemer G. Mitotic catastrophe: a mechanism for avoiding genomic instability. Nat Rev Mol Cell Biol 2011;12(6):385-92.

82. Vitale I, Galluzzi L, Senovilla L, et al. Illicit survival of cancer cells during polyploidization and depolyploidization. Cell Death Differ 2011;18(9):1403-13.

83. Schaue D, Micewicz ED, Ratikan JA, et al. Radiation and inflammation. Semin Radiat Oncol 2015;25(1):4-10.

84. Kawai T, Akira S. Toll-like receptors and their 
crosstalk with other innate receptors in infection and immunity. Immunity 2011;34(5):637-50.

85. Schaue D, Kachikwu EL, McBride WH. Cytokines in radiobiological responses: a review. Radiat Res 2012;178(6):505-23.

86. Schaue $D, M c B r i d e ~ W H$. Links between innate immunity and normal tissue radiobiology. Radiat Res 2010;173(4):406-17.

87. Garg AD, Dudek-Peric AM, Romano E, Agostinis P. Immunogenic cell death. Int J Dev Biol 2015;59(1-3):131-40.

88. Kroemer G, Galluzzi L, Kepp O, Zitvogel L. Immunogenic cell death in cancer therapy. Annu Rev Immunol 2013;31:51-72.

89. Galluzzi L, Vitale I, Aaronson SA, et al. Molecular mechanisms of cell death: recommendations of the Nomenclature Committee on Cell Death 2018. Cell Death Differ 2018;25(3):486-541.

90. Kono K, Mimura K. Immunogenic tumor cell death induced by chemoradiotherapy in a clinical setting. Oncoimmunology 2013;2(1):e22197.

91. Aoto K, Mimura K, Okayama H, et al. Immunogenic tumor cell death induced by chemotherapy in patients with breast cancer and esophageal squamous cell carcinoma. Oncol Rep 2018;39(1):151-9.

92. Tchkonia T, Zhu Y, van Deursen J, Campisi J, Kirkland JL. Cellular senescence and the senescent secretory phenotype: therapeutic opportunities. J Clin Invest 2013;123(3):966-72.

93. Verheij M. Clinical biomarkers and imaging for radiotherapy-induced cell death. Cancer Metastasis Rev 2008;27(3):471-80.

94. Chou CH, Chen PJ, Lee PH, et al. Radiation-induced hepatitis $\mathrm{B}$ virus reactivation in liver mediated by the bystander effect from irradiated endothelial cells. Clin Cancer Res 2007;13(3): 851-7.

95. Narayanan PK, LaRue KE, Goodwin EH, Lehnert BE. Alpha particles induce the production of interleukin-8 by human cells. Radiat Res 1999;152(1):57-63.

96. Zhou H, Ivanov VN, Gillespie J, et al. Mechanism of radiation-induced bystander effect: role of the cyclooxygenase-2 signaling pathway. Proc Natl Acad Sci USA 2005;102(41):14641-6.

97. Iyer $R$, Lehnert $B E$, Svensson R. Factors underlying the cell growth-related bystander responses to alpha particles. Cancer Res 2000;60(5):1290-8.

98. Mothersill C, Seymour CB. Radiation-induced bystander effects--implications for cancer. Nat Rev Cancer 2004;4(2):158-64.
99. Golden EB, Formenti SC. Is tumor (R)ejection by the immune system the " 5 th $\mathrm{R}$ " of radiobiology? Oncoimmunology 2014;3(1):e28133.

100. Grabham P, Sharma P. The effects of radiation on angiogenesis. Vasc Cell 2013;5(1):19.

101. Koukourakis MI, Giatromanolaki A, Sivridis E, Fezoulidis I. Cancer vascularization: implications in radiotherapy? Int J Radiat Oncol Biol Phys 2000;48(2):545-53.

102. Yoshimura M, Itasaka S, Harada H, Hiraoka M. Microenvironment and radiation therapy. Biomed Res Int 2013;2013:685308.

103. Park HJ, Griffin RJ, Hui S, Levitt S/H, Song CW. Radiation-induced vascular damage in tumors: implications of vascular damage in ablative hypofractionated radiotherapy (SBRT and SRS). Radiat Res 2012;177(3):311-27.

104. Kozin SV, Duda DG, Munn LL, Jain RK. Neovascularization after irradiation: what is the source of newly formed vessels in recurring tumors? J Natl Cancer Inst 2012;104(12):899-905.

105. Hellevik T, Martinez-Zubiaurre I. Radiotherapy and the tumor stroma: the importance of dose and fractionation. Front Oncol 2014;4:1.

106. Sundahl N, Duprez F, Ost P, De Neve W, Mareel $M$. Effects of radiation on the metastatic process. Mol Med 2018, 24(1):16.

107. Wachsberger P, Burd R, Dicker AP. Tumor response to ionizing radiation combined with antiangiogenesis or vascular targeting agents: exploring mechanisms of interaction. Clin Cancer Res 2003;9(6):1957-71.

108. Wachsberger P, Burd R, Dicker AP. Improving tumor response to radiotherapy by targeting angiogenesis signaling pathways. Hematol Oncol Clin North Am 2004;18(5):1039-57.

109. Kanthou, C., Tozer, G. Targeting the vasculature of tumours: combining VEGF pathway inhibitors with radiotherapy. Br J Radiol 2018;5:20180405.

110. Postow MA, Callahan MK, Barker CA, et al. Immunologic correlates of the abscopal effect in a patient with melanoma. N Engl J Med 2012;366(10):925-31.

111. Stamell EF, Wolchok JD, Gnjatic S, Lee NY, Brownell I. The abscopal effect associated with a systemic anti-melanoma immune response. Int J Radiat Oncol Biol Phys 2013;85(2):293-5.

112. Koller KM, Mackley HB, Liu J, et al. Improved survival and complete response rates in patients with advanced melanoma treated with concurrent ipilimumab and radiotherapy 
versus ipilimumab alone. Cancer Biol Ther 2017; 18(1):36-42.

113. Wersäll PJ, Blomgren H, Pisa P, et al. Regression of non-irradiated metastases after extracranial stereotactic radiotherapy in metastatic renal cell carcinoma. Acta Oncol 2006;45(4): 493-7.

114. Ishiyama $H$, The BS, Ren $H$, et al. Spontaneous regression of thoracic metastases while progression of brain metastases after stereotactic radiosurgery and stereotactic body radiotherapy for metastatic renal cell carcinoma: abscopal effect prevented by the blood-brain barrier? Clin Genitourin Cancer 2012;10(3):196-8.

115. Siva S, Callahan J, MacManus MP, et al. Abscopal [corrected] effects after conventional and stereotactic lung irradiation of non-small-cell lung cancer. J Thorac Oncol 2013;8(8):e71-2.

116. Chicas-Sett R, Morales-Orue I, Rodriguez-Abreu D, Lara-Jimenez P. Combining radiotherapy and ipilimumab induces clinically relevant radiation-induced abscopal effects in metastatic melanoma patients: A systematic review. Clin Transl Radiat Oncol 2017;9:5-11.

117. Yin L, Xue J, Li R, et al. Effect of Low-Dose Radiation Therapy on Abscopal Responses to Hypofractionated Radiation Therapy and Anti-PD1 in Mice and Patients with Non-Small Cell Lung Cancer. Int J Radiat Oncol Biol Phys 2020;108(1):212-24.

118. Dewan MZ, Galloway AE, Kawashima N, et al. Fractionated but not single-dose radiotherapy induces an immune-mediated abscopal effect when combined with anti-CTLA-4 antibody. Clin Cancer Res 2009;15(17):5379-5388.

119. Romano G. Latest advances in gene transfer: A summary of the 14th Annual Meeting of the American Society of Gene \& Cell Therapy. Drugs Fut 2011;36(7):535-41.

120. Lichty BD, Breitbach CJ, Stojdl DF, Bell JC. Going viral with cancer immunotherapy. Nat Rev Cancer 2014;14(8):559-67.

121. Russell L, Peng KW. The emerging role of oncolytic virus therapy against cancer. Chin Clin Oncol 2018;7(2):16.

122. Achard C, Surendran A, Wedge ME, et al. Lighting a Fire in the Tumor Microenvironment Using Oncolytic Immunotherapy. EBioMedicine 2018;31:17-24.

123. Martin NT, Bell JC. Oncolytic Virus Combination Therapy: Killing One Bird with Two Stones. Mol Ther 2018;26(6):1414-22.
124. Russell SJ, Barber GN. Oncolytic Viruses as Antigen-Agnostic Cancer Vaccines. Cancer Cell 2018;33(4):599-605.

125. Guan M, Ma Y, Shah SR, Romano G. Thyroid malignant neoplasm-associated biomarkers as targets for oncolytic virotherapy. Oncolytic Virother 2016;5:35-43.

126. Guan M, Romano G, Coroniti R, Henderson EE. Progress in oncolytic virotherapy for the treatment of thyroid malignant neoplasm. J Exp Clin Cancer Res 2014;33:91.

127. Grigg C, Blake Z, Gartrell R, et al. Talimogene laherparepvec (T-Vec) for the treatment of melanoma and other cancers. Semin Oncol 2016;43(6):638-46.

128. Bommareddy PK, Patel A, Hossain S, Kaufman HL. Talimogene Laherparepvec (T-VEC) and Other Oncolytic Viruses for the Treatment of Melanoma. Am J Clin Dermatol 2017;18(1):1-15.

129. Fukuhara $H$, Ino $Y$, Todo T. Oncolytic virus therapy: A new era of cancer treatment at dawn. Cancer Sci 2016;107(10):1373-9.

130. Ott PA, Hodi FS. Talimogene Laherparepvec for the Treatment of Advanced Melanoma. Clin Cancer Res 2016;22(13):3127-31.

131. Kaufman $\mathrm{HL}$, Amatruda $\mathrm{T}$, Reid $\mathrm{T}$, et al. Systemic versus local responses in melanoma patients treated with talimogene laherparepvec from a multi-institutional phase II study. J Immunother Cancer 2016;4:12.

132. Cavalcante L, Chowdhary A, Sosman JA, Chandra S. Combining Tumor Vaccination and Oncolytic Viral Approaches with Checkpoint Inhibitors: Rationale, Pre-Clinical Experience, and Current Clinical Trials in Malignant Melanoma. Am J Clin Dermatol 2018.

133. Harrington KJ, Puzanov I, Hecht JR, et al. Clinical development of talimogene laherparepvec (T-VEC): a modified herpes simplex virus type1-derived oncolytic immunotherapy. Expert Rev Anticancer Ther 2015;15(12):1389-403.

134. Kohlhapp FJ, Zloza A, Kaufman HL. Talimogene laherparepvec (T-VEC) as cancer immunotherapy. Drugs Today (Barc) 2015;51(9):549-58.

135. Puzanov I, Milhem MM, Minor D, et al. Talimogene laherparepvec in combination with ipilimumab in previously untreated, unresectable stage IIIB-IV melanoma. J Clin Oncol 2016; 34(22):2619-26.

136. Fend L, Yamazaki T, Remy C, et al. Immune Checkpoint Blockade, Immunogenic Chemotherapy or IFN-a Blockade Boost the Local 
and Abscopal Effects of Oncolytic Virotherapy. Cancer Res 2017;77(15):4146-57.

137. Choi AH, O' Leary MP, Chaurasiya S, et al. Novel chimeric parapoxvirus CF189 as an oncolytic immunotherapy in triple-negative breast cancer. Surgery 2018;163(2):336-42.

138. Yamazaki T, Pitt JM, Vétizou $M$, et al. The oncolytic peptide LTX-315 overcomes resistance of cancers to immunotherapy with CTLA4 checkpoint blockade. Cell Death Differ 2016, 23(6):1004-15.

139. Joiner JB, Pylayeva-Gupta Y, Dayton PA. Focused Ultrasound for Immunomodulation of the Tumor Microenvironment. J Immunol 2020;205(9):2327-41.

140. Napoli A, Alfieri G, Scipione R, et al. High-intensity focused ultrasound for prostate cancer. Expert Rev Med Devices 2020;17(5):427-33.

141. Ahdoot M, Lebastchi AH, Turkbey B, Wood B, Pinto PA. Contemporary treatments in prostate cancer focal therapy. _Curr Opin Oncol 2019;31(3):200-6.

142. Mondini M, Levy A, Meziani L, Milliat F, Deutsch E. Radiotherapy-immunotherapy combinations - perspectives and challenges. Mol Oncol 2020;14(7):1529-37. 